SCIENTIFIC LETTER

\title{
Similarities in the profile of cardiopulmonary exercise testing between patients with hypertrophic cardiomyopathy and strength athletes
}

\author{
A Anastasakis, C Kotsiopoulou, A Rigopoulos, A Theopistou, N Protonotarios, D Panagiotakos, \\ N Mammalis, C Stefanadis
}

Heart 2005;91:1477-1478. doi: 10.1136/hrt.2004.055053

$\mathrm{D}$

fferentiating between young, athletic patients with hypertrophic cardiomyopathy (HCM) and elite athletes sometimes can be problematic. ${ }^{1-4}$ Left ventricular hypertrophy is seen mainly in athletes participating in endurance sports. ${ }^{1}$ A conflict exists with regard to strength athletes. ${ }^{2}$ Recent investigations suggest that strength athletes who use anabolic steroids have increased left ventricular hypertrophic response to exercise ${ }^{2}$ compared with drug-free, sport matched athletes. Therefore, in some cases athletic, young patients with HCM and strength athletes must also be differentiated.

Cardiopulmonary exercise testing (CET) metabolic parameters have been considered to contribute to differentiating patients with HCM from athletes participating in endurance sports. ${ }^{1}$ However, the metabolic profiles of patients with $\mathrm{HCM}^{5}$ and of strength athletes have not yet been compared.

The objective of the present study was to identify the relation between the CET profiles of young, male athletic patients with HCM and the profiles of elite, male strength athletes, and to question the value of CET in differentiating patients with HCM from strength athletes.

\section{METHODS}

For this study, 19 strength athletes from the Greek Olympic weight lifting team, 20 endurance athletes (middle and long distance runners) from the national team, and 27 patients with HCM with recent physical activity (mainly aerobic type) were compared. All patients had diagnosed non-obstructive HCM. They were subjectively asymptomatic and were traced through pre-participation athletic screening. None of the patients with HCM was taking any form of medication. They all had an abnormal resting ECG. All athletes were asymptomatic and none of them had a family history of HCM, other cardiovascular disease, or premature sudden cardiac death.

All subjects underwent a maximal ramp cycle ergometer exercise test with simultaneous gas exchange analysis. ${ }^{156}$ Peak and submaximal metabolic parameters during CET of the three groups were compared.

Continuous and categorical variables were compared by the Kruskal-Wallis test as well as one way analysis of variance after testing for equality of variances (homoscedasticity). Correlations between variables were evaluated by the use of Spearman's $\rho$ coefficient. SPSS 11.0 software (SPSS Inc, Chicago, Illinois, USA) was used for all the statistical calculations.

\section{RESULTS}

In the present study, three of the 19 strength athletes (16\%) had a wall thickness of $13 \mathrm{~mm}$. All participants in the study exercised to exhaustion and stopped due to leg fatigue. The mean (SD) duration of exercise was 10.2 (2) minutes. They all had a normal blood pressure response.

Elite endurance athletes had higher peak oxygen consumption $\left(\mathrm{pVO}_{2}\right)$, percentage of predicted $\mathrm{Vo}_{2}$, anaerobic threshold, percentage of predicted anaerobic threshold, and oxygen pulse than strength athletes and patients with HCM $(\mathrm{p}<0.05)$. None of the CET parameters differed significantly between strength athletes and patients with HCM. The minute ventilation/carbon dioxide production $\left(\mathrm{VE} / \mathrm{VCO}_{2}\right)$ slope was decreased $(p<0.001)$ in the endurance athletes compared with strength athletes and patients with HCM but did not differ between patients with HCM and strength athletes. The $\Delta \mathrm{VO}_{2} / \Delta$ work rate (WR) slope was not significantly different between the three groups.

Table 1 shows the echocardiographic and CET parameters of all participants.

\section{DISCUSSION}

The similarities that have been found in the CET parameters between patients with HCM and strength athletes raise questions as to whether metabolic exercise testing can also contribute to differentiating patients with HCM from strength athletes.

\section{The hypertrophy issue}

The effects of strength training on left ventricular morphology remain equivocal. ${ }^{2-4}$ The disparity in the results of studies on whether strength athletes consistently develop cardiac hypertrophy may be caused by the specific type of strength training performed, the age of the athlete, the genetic predisposition of the athlete, and the underlying use of anabolic steroids. ${ }^{2}$ The present data, where the left ventricular hypertrophy range of the weightlifters was 9-13 mm, also strengthen our position that differential diagnosis is problematic in certain strength athletes. In the present study, we did not take into account whether the patients with HCM and the elite athletes had the same degree of left ventricular wall thickness (hypertrophy), since recent studies ${ }^{5}$ indicate that left ventricular hypertrophy alone is not related to exercise capacity in HCM.

\section{Cardiopulmonary parameters}

Participation in endurance training induces increases in $\mathrm{pVO}_{2}$, whereas training for many strength athletes underestimates the aerobic component. The functional limitation (reduced $\mathrm{pVO}_{2}$ ) that was found in the weightlifters can mainly be attributed to the adaptations of their peripheral skeletal muscles to strength training. Various mechanisms

Abbreviations: CET, cardiopulmonary exercise testing; $\mathrm{HCM}$, hypertrophic cardiomyopathy; $\mathrm{pVO}_{2}$, peak oxygen consumption; $\mathrm{VCO}_{2}$, carbon dioxide production; VE, minute ventilation; WR, work rate 
Table 1 Echocardiographic and cardiopulmonary exercise testing parameters in patients with hypertrophic cardiomyopathy $(\mathrm{HCM})$ and in strength and endurance athletes

\begin{tabular}{|c|c|c|c|c|}
\hline Parameter & $\mathrm{HCM}(n=27)$ & Strength $(n=19)$ & Endurance $(n=20)$ & p Value \\
\hline Age (years) & $19.90(6.27)$ & $22.60(3.89)$ & $22.00(3.24)$ & NS \\
\hline Weight (kg) & $75.77(13.54)$ & $83.74(13.37)$ & $80.45(7.38)$ & NS \\
\hline LVWT (mm) & $18.64(5.54)^{*}$ & $10.74(1.40)$ & $10.10(0.91)$ & $<0.05$ \\
\hline Range & $13-35$ & $9-13$ & $9-12$ & \\
\hline LVEDD (mm) & $45.24(4.81)^{*}$ & $50.42(2.87) \dagger$ & $55.68(3.23)$ & $<0.05$ \\
\hline Range & $36-54$ & $44-58$ & $46-59$ & \\
\hline $\mathrm{pVO}_{2}(\mathrm{ml} / \mathrm{kg} / \mathrm{min})$ & $33.43(6.84)$ & $31.51(2.75)$ & 58.09 (4.59)‡ & $<0.001$ \\
\hline $\mathrm{pVO}_{2} \%$ & $77.70(12.25)$ & $73.89(6.70)$ & $136.40(11.51) \ddagger$ & $<0.001$ \\
\hline AT $(\mathrm{l} / \mathrm{min})$ & $1.21(0.26)$ & $1.18(0.22)$ & $2.54(0.41) \ddagger$ & $<0.001$ \\
\hline AT $\%$ & $38.11(8.39)$ & $34.11(5.39)$ & 74.55 (10.99)‡ & $<0.001$ \\
\hline $\mathrm{O}_{2} \mathrm{P}$ (ml/beat) & $13.93(2.43)$ & $14.97(1.73)$ & $25.35(2.68) \ddagger$ & $<0.001$ \\
\hline$\Delta \mathrm{VO}_{2} / \Delta \mathrm{WR}(\mathrm{ml} / \mathrm{min} / \mathrm{W})$ & $9.58(0.93)$ & $8.96(1.03)$ & $9.21(0.87)$ & NS \\
\hline $\mathrm{VE} / \mathrm{VCO}_{2}$ slope & $27.38(3.74)$ & $25.65(1.76)$ & $22.36(1.84) \ddagger$ & $<0.001$ \\
\hline \multicolumn{5}{|c|}{ 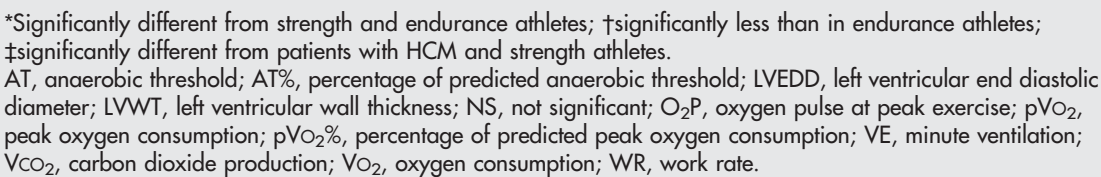 } \\
\hline
\end{tabular}

cause the exercise limitation in patients with HCM, which has been found to be lower than in controls. ${ }^{5}$

The reduced anaerobic threshold in patients with HCM is indicative of an increased anaerobic contribution at an earlier stage during exercise, which may be the result of reduced oxygen delivery to working muscles. Similarly, the reduced anaerobic threshold in strength athletes indicates an increased anaerobic contribution, which can be attributed to peripheral muscle adaptations in these athletes. The low oxygen pulse in patients with HCM is due to diastolic dysfunction and decreased end diastolic volume. In the weightlifters, low oxygen pulse may be attributed to the poor utilisation of oxygen by the peripheral muscles.

The patients with HCM had a mean (SD) $\Delta \mathrm{VO}_{2} / \Delta \mathrm{WR}$ of 9.6 (0.9), which is within the normal range, ${ }^{5}$ since these physically active patients were participating in aerobic activities just before the diagnosis. The weightlifters, mainly due to peripheral adaptations, had a low $\mathrm{pVO}_{2}$, a high ratio of anaerobic to aerobic work, and a slope of 8.9 (1.0), which is close to the lower limits of the normal range.

The patients with HCM had a $\Delta \mathrm{VE} / \Delta \mathrm{VCO}_{2}$ of less than 30 , which does not agree with previous studies. ${ }^{6}$ However, it should be noted that our patients with HCM were athletic, whereas $\Delta \mathrm{VE} / \Delta \mathrm{VCO}_{2}$ has been found to increase in severe forms of heart failure. ${ }^{7}$ In weightlifters, an earlier onset of lactic acidosis during exercise due to their peripheral muscle adaptations and additional hyperventilation may contribute to the overlap between patients with HCM and weightlifters.

The results of the present study show that, due to different underlying reasons in each case, the maximal and submaximal metabolic parameters of strength athletes and patients with HCM overlap. Although CET is an established method for differentiating between patients with HCM and endurance athletes, it has severe limitations when assessing strength athletes.

\section{Authors' affiliations}

A Anastasakis, C Kotsiopoulou, A Rigopoulos, A Theopistou,

N Protonotarios, N Mammalis, C Stefanadis, Department of

Cardiology, University of Athens, Athens, Greece

D Panagiotakos, Department of Dietetics and Nutrition, Harokopio University, Athens, Greece

Supported by: General Secretariat of Sports, Ministry of Culture, General Secretariat of Youth, Ministry of Education

Correspondence to: Dr Aristides Anastasakis, 32, Al Papanastasiou str, N Psihiko, Athens 154 51, Greece; sotoaris@ath.forthnet.gr

Accepted 7 April 2005

\section{REFERENCES}

1 Sharma S, Elliott PM, Whyte G, et al. Utility of metabolic exercise testing in distinguishing hypertrophic cardiomyopathy from physiologic left ventricular hypertrophy in athletes. J Am Coll Cardiol 2000;36:864-70.

2 Payne JR, Kotwinski PJ, Montgomery HE. Cardiac effects of anabolic steroids. Heart 2004;90:496-501.

3 American College of Cardiology, European Society of Cardiology. ACC/ESC expert consensus document on hypertrophic cardiomyopathy. Eur Heart $J$ 2003;24:1965-91.

4 Pluim BM, Aeilko HZ, van der Laarse A, et al. The athlete's heart: a metaanalysis of cardiac structure and function. Circulation 1999;100:336-44.

5 Sharma S, Elliott PM, Whyte G, et al. Utility of cardiopulmonary exercise in the assessment of clinical determinants of functional capacity in hypertrophic cardiomyopathy. Am J Cardiol 2000;86:162-8.

6 Wasserman K, Hansen JE, Sue DY, et al. Principles of exercise testing and interpretation, 2nd ed. London: Lea and Febiger, 1994, 80-94, 255-275.

7 Wasserman K, Hansen JE, Sue DY, et al. Principles of exercise testing \& interpretation: including pathophysiology and clinical applications, 3rd ed. Philadelphia: Lippincott Williams \& Wilkins, 1999:155. 